\title{
Alejandro de Humboldt
}

\section{El viaje memorable por el Perú*}

o acompañaban su colaborador, el botánico francés Aimé Bonpland, el pintor ecuatoriano Hipólito Ruiz y su amigo de Quito, el joven Carlos Montúfar. Viniendo de Loja, ingresó a lomo de mula por Lucarque y Ayabaca para continuar a Chulucanas, Huancabamba y San Felipe. Seguía casi la misma ruta que La Condamine 50 años atrás. Su propósito era acercarse a Jaén y de allí llegar al río Marañón. En efecto, por Jaén alcanzó el 15 de agosto la ribera del Marañón a la altura de Tomependa, situada en la confluencia de ese río con el Chinchipe, donde permaneció una quincena. Tuvo allí la perfecta visión de la selva peruana. Como el tiempo lo apremiaba, inició el regreso a la zona andina para alcanzar Cajamarca, después de haberse detenido en Montán y Hualgayoc. El 19 de septiembre, dejando Cajamarca, tramontó la divisora de los Andes y descendió hacia la vertiente occidental por la Magdalena y Contumazá. Desde el Alto de Huangamarca tuvo Humboldt, a $100 \mathrm{~km}$ de distancia, la primera y espléndida visión del Mar del Sur, que todavía no había tenido ante sus ojos, no obstante, haber atravesado los actuales territorios de Colombia y Ecuador. Desde este punto enfiló al valle

* Agradecemos a don Estuardo Núńez Hague por la gentileza de concedernos el permiso para presentar este escrito, que fue publicado en Libros y Artes: revista de cultura de la Biblioteca Nacional, N.o 4, abril 2003, Lima, pp. 16-20. 
de Chicama, por Cascas y Chala, para alcanzar Trujillo el 23 de septiembre. Visita allí ruinas extraordinarias que despiertan su admiración y pueblos vecinos con prósperos cultivos. El 7 de octubre continúa el viaje a Lima, a través de interminables arenales, utilizando el transporte por literas, montadas sobre mulas, usual desde muchos años atrás. El viaje rompe su monotonía sólo en los valles como Virú y Santa, cuyo río cruza en balsa. El 12 de octubre arriba a Chimbote, entonces denominado Ferrol, donde recibe la primera noticia del guano de las islas, experiencia que vuelve a tener en Huaura y el Callao. La siguiente escala de importancia fue Huambacho, en la margen del río Samanco. Luego llega a Casma, Huarmey, Barranca y Huaura (el 19 de octubre). El 20 se detiene en las Salinas de Huacho, y al día siguiente pasa por Chancay y finalmente ingresa a Lima, por la Portada de Guía, el 23 de octubre en la noche.

En dos meses de estadía en Lima de actividad infatigable: observaciones astronómicas, meteorológicas, pesquisas bibliográficas, lecturas en las bibliotecas de Unanue y Urquizo, del padre Diego Cisneros y el barón de Nordenflycht (quien tenía su laboratorio en la Alameda de los Descalzos), visitas al padre Girbal, al matemático José Gregorio Paredes, a los botánicos Tafalla y Manzanilla (entonces residentes en Lima), al protomédico Aguirre y al regente Arredondo, y a tantos más que pudieran allegarle datos o referencias para sus trabajos. Atiende su correspondencia, la cual pone al día después de meses de interrupción. Despacha colecciones del Mercurio Peruano destinadas al poeta Goethe, su amigo. Mide la temperatura del mar en el Callao y comprueba la calidad de las rocas graníticas entre el Morro Solar de Chorrillos y la isla de San Lorenzo. Finalmente, observa el paso de Mercurio delante del disco solar el 9 de noviembre, a lo cual agrega múltiples observaciones de toda índole, producidas entre noviembre y diciembre de 1802. Zarpó del Callao rumbo a Guayaquil en la tarde del 24 de diciembre de 1802.

Ningún fenómeno natural o humano ni ninguna rama del saber escaparon a su penetrante don de observación. Sus apuntes de viaje abarcan todos los conocimientos; desde la botánica, zoología, geología, geografía, etnografía y arqueología hasta la economía, industria, minería y la situación social y política, las lenguas aborígenes y la historia antigua del Perú.

u sentido de universalidad puede advertirse tanto en la profundidad de sus indagaciones
sobre la realidad observada y vivida como en la extensión de su visión, que no se limitó a un solo país sino que abarcó continentes y el universo entero, de lo cual es testimonio 
la obra en que resume su concepción del mundo titulada Kosmos, una de las últimas que escribió en las postrimerías de su intensa vida.

Es significativo que la mayor parte de la ingente obra legada por Humboldt a la posteridad sea dedicada a las diferentes zonas de América que recorrió en su memorable y único viaje de 1799 a 1804 . Cuando hizo esto en otros terrenos y otras materias queda muy por debajo de su obra dedicada a América. Contribuyó a su buen éxito la época propicia en que realizó el viaje, o sea, los ańos que precedieron a las campañas de la emancipación americana. Estaba en forma el espíritu de los hombres para recibir nuevos planteamientos científicos, así como las ciencias empezaban también la recepción de nuevas ideas en el campo político y filosófico. Le tocó vivir en una época de profunda crisis y transformaciones, tanto en Europa como en América. Allí campeaba la expansión napoleónica en todo su vigor. Aquí se preparaban los primeros estallidos revolucionarios, a ejemplo de la democracia norteamericana.

Encabalgada en esos años cruciales, su labor científica consiste en desconocer el velo sobre la naturaleza americana, apenas hallada por los misioneros en siglos precedentes. Se ha dicho, por lo tanto, que Humboldt es el descubridor científico de América y que «hizo más por ella que todos los conquistadores». Esta frase, atribuida a Bolívar, se tiñe de la intolerancia ideológica del liberalismo del siglo xix, que se volcaba en un antiespañolismo indiscriminado. Más para explicar a Humboldt no es preciso denigrar los aportes de la ciencia española con relación a América ni las virtudes innegables de la colonización hispánica ni el mérito del gobierno español al brindar al propio Humboldt las facilidades requeridas para realizar sus recorridos e investigaciones en las colonias de Espańa. Contrasta este generoso apoyo, que él reconoció siempre como excelente, con las oposiciones que encontró en el territorio portugués al otro lado del Orinoco o con las limitaciones y restricciones que pacientemente sufrió y lamentó en su viaje al Asia central, de parte del despótico gobierno ruso de Alejandro I. Por lo demás, a lo largo de su obra americanista, Humboldt rindió tributo de admiración por las expresiones del espíritu español volcadas sobre América, citando profusamente a Cieza de León, a Garcilaso de la Vega, al jesuita Acosta, al cronista Gómara, a viajeros como Azara, Juan y Ulloa, a los botánicos Ruiz y Pavón, a los científicos como Mutis y Clavijo, y a otros hispanoamericanos en quienes atisba el genio de investigadores como Caldas, Hipólito Unanue, y Andrés del Río. Aparte de México, país al que dedicó un volumen de especial significación, su Ensayo político sobre el reino de Nueva España, además de Cuba, país al que brindó un estudio similar, y de 
Venezuela, a la que gracia con su monumental Viaje a las regiones equinoxiales del Nuevo Continente, en cinco volúmenes, casi en su integridad el resto de los países por él recorridos (Colombia, Ecuador y Perú) no llegaron a merecer, por circunstancias del destino, un relato de viaje especificado. No obstante, dentro de la ingente obra de Humboldt se encuentran dispersos múltiples trabajos relacionados con estos países menos favorecidos, y con ellos y con datos diseminados entre los números de sus observaciones meteorológicas, altimétricas, botánicas, geológicas y oceanografías se puede reconstruir su derrotero y realizar el balance de su estupenda empresa científica.

Enloqueserefiereal Perú, podemos precisarsuaportefundamentalenladeterminación científica de lugares geográficos; sus observaciones astronómicas complementarias a esa labor geográfica; sus estudios meteorológicos (antes sólo empíricamente formuladas, básicos sobre todo para establecer la verdadera naturaleza del clima de la costa peruana); sus observaciones geológicas y volcánicas que dan luz nueva sobre la estructura de la cadena andina de la costa sudamericana del Pacífico; sus recolecciones botánicas que ofrecen nuevos aspectos, antes ignorados, de la calidad de la flora sudamericana; sus observaciones sobre animales típicos como la llama y la vicuña, el perro aborigen de estas regiones, y el cóndor y el flamenco; así como la determinación científica del valor práctico de los yacimientos del guano en la costa y en las islas del litoral del Perú, y sobre el cultivo de la quina; el planteamiento de los estudios oceanográficos con proyecciones para la navegación y la explotación de la fauna marina, y, finalmente, sus observaciones y consejos sobre la mejor administración política y económica de esas regiones de la América Meridional, abandonadas por la administración española y su esperanza de que esos errores serían enmendados por los hombres del país (los criollos, cuya inteligencia e inquietud es lo primero en reconocer plenamente, y en quienes deposita su esperanza de que un día, alcanzada la autonomía, puedan emprender una obra magna de organizar definitivamente estos territorios para hacer la felicidad de sus habitantes y alcanzar el puesto que la América merece en el concierto de los pueblos civilizados, prósperos y libres).

América constituye para Humboldt la razón de su vida y su destino. El nuevo continente embarga su inquietud desde sus años juveniles. Su maestro Joaquín Enrique Campe despertaba en él prematuramente el interés por estas regiones y alimentaba su fantasía. Campe había escrito una Historia de América y había traducido al alemán el Robinson Crusoe de Defoe. Más tarde, a la novelística convencional de Defoe, se agregarán los relatos de Jorge Forster sobre sus viajes por un sector de América hacia los Mares del Sur, 
en compañía de Cook, y las narraciones de La Condamine y Bougainville. A través de las creaciones de Rousseau y Bernardino de Saint Pierre, debía también en el «utopismo» de la época de la ilustración, cuya primera inspiración se sustentaba en relatos sobre el Nuevo Mundo a partir del siglo XvI.

$\mathrm{L}^{\prime}$ legada la madurez, Humboldt enfoca ya a la América como una realidad concreta, como un campo de investigación y de experiencia humana. Realiza su viaje y escribe en el resto de su vida el producto del caudal enorme de sus observaciones y estudios. Y finalmente, en la vejez laboriosa y activa, recordando siempre su inolvidable vivencia americana, creó una legión de discípulos que vinieron a América a continuar, en diferentes campos, su mensaje científico. No se cansa Humboldt, pese a lo recargado de sus ocupaciones, de dar instrucciones y consejos a los nuevos investigadores de cosas americanas. Sucedió esto con Mariano Eduardo de Rivero y Ustáriz, Hipólito Unanue, Carlos Scherzer y Hermann Burneister, Alcides D’Orbigny, Louis Agassiz y Adolfo Bandelier (a quienes ayudó a establecerse en América del Norte para que más tarde viajaran por América meridional). Sucedió así también con Schomburgk (viajero en la Guayana), a más de uno incitó (indirectamente a través de sus libros) la curiosidad americanista de Carlos Darwin, William Prescott, Eduardo Seler, John Lloyd Stephens en Yucarán, y George Squier en Perú.

Toda la influencia personal y política adquirida en sus últimos años, la empeñaba en favorecer el trabajo de esos discípulos continuadores de su obra. Sońaba con la creación de un gran establecimiento científico en México al lado de sus discípulos, en donde pudiera orientar toda esa portentosa actividad científica que planeaba. Con el léxico de su gran amigo y admirador Goethe podría afirmarse que América fue en Humboldt verdad y poesía, una obsesión vital que se armonizaba la observación y deducción o inducción metódica de la realidad tangible y por él conocida de primera mano, con el idealismo de un ensueño por realizar, en una América que fuera el asiento de la esperanza de la humanidad.

El puesto de Humboldt en la cultura peruana es significativo. Podría decirse que cierra una etapa y que abre, con genial intuición, otra. Los alemanes, además de los espańoles, están presentes en América, ya desde antes de la conquista del Perú, en los ajetreos previos a esta empresa trascendental. Se encuentran en las negociaciones para la conquista de América, en la preparación de contratos con Carlos V destinados a la explotación y 
colonización de Tierra Firme (Venezuela) en 1530, además fijan zonas de penetración y expansión que comprenden el Perú (antes de que surgieran sobre el tapete de la historia Pizarro y Almagro). Luego, concurren alemanes al acto mismo de la conquista, confundidos con los soldados españoles conquistadores. Afirmada la colonia, en el XVII, algún alemán viene mezclado con las huestes de corsarios holandeses y escribe su propia relación. Éste es el marino Adolfo Decker de Estrasburgo, que había participado en la expedición de L'Hermite, y que fue testigo presencial de su descalabro frente al Callao. A fines del mismo siglo, y también en el XviII, empiezan a asomarse por estas costas de la América Meridional los primeros viajeros científicos. Se adelantaron los españoles, los franceses Feuillée, Frezier y La Condamine y algo los ingleses; pero no desmerecen en su fruición por lo exótico y lo desconocido los viajeros de origen germánico, como el bohemio Tadeo Haenke o el austríaco Helms.

Por un lado, en las bravías selvas amazónicas o en las punas inclementes se hacen útiles al desarrollo cultural del país, los clérigos misioneros tudescos, entre los que destacan: los padres Samuel Fritz, Franz Xavier Veigl, Heinrich Richter, Juan Rehr (muchos más en el Amazonas) y los padres también jesuitas Wolfgang Bayer y Francisco Eder en las inhóspitas regiones del Collao y Moxos, todos geógrafos, lingüistas y hasta larvados antropólogos. Este es el cuadro somero de los viajeros alemanes que antecedieron a Humboldt en la América Meridional. Ellos se limitaron a trazar el bosquejo del recorrido, a observar científicamente y a estar atentos de los usos y costumbres de los habitantes. Los grandes viajeros anteriores españoles y franceses habían participado de este fragmentario interés por el hombre de estas regiones, más que por el paisaje. Por otro lado, los grandes viajeros marinos ingleses, como Drake, Hawkins, Dampier, Anson y Cook, con excepción del último, agregaban a ese interés una consigna política de penetración y examen de condiciones sociales y económicas que viene a caracterizar al viajero anglosajón. De todos modos, unos y otros habían excitado la imaginación de los europeos ( $y$, sin duda, la del propio Humboldt) y alimentaron la fantasía de los poetas y escritores del siglo xviII e inicios del xix coincidentes en ese rasgo común en los comienzos del Romanticismo.

Decíamos que Humboldt cerró esa etapa y, en la aurora del siglo xIx, abrió las compuertas de una nueva era en la observación de la realidad americana. Sin perder su fuerza ideal, sin despojarse de su intuición poética ni de su sentido universal de la vida, Humboldt empieza a usar un método más positivo, una observación más sistemática de los fenómenos concretos. Lo sugestionan los acontecimientos reales, la verdadera condición 
del hombre, la realidad antes que la leyenda, la observación científica antes que la fantasía o el hecho imaginario. Humboldt es el más completo de los viajeros venidos hasta ese momento.

Su observación es metódica y exacta gracias al empleo de métodos de viaje, asegura que sus resultados estarán exentos de empirismo o improvisación. Pero los hechos físicos deben ser confrontados con los espirituales. Le preocupan a Humboldt el hombre de estas regiones y las sociedades que ha formado. La observación del fenómeno natural va conjugando con el estudio del fenómeno social. Su ideología liberal, fortalecida al calor de los ideales de la Revolución Francesa y de la política europea de su época (desde aquella tarde espléndida en que presenció en París el juramento del Campo de Marte, en compañía de su amigo Jorge Forster) lo hacía pronunciarse con repugnancia ante la observación, en varias partes de América, de la explotación del hombre por el hombre, y ofrecer su juicio contrario a la esclavitud en cualquiera de sus formas. Esa inquietud social lo llevó a pronosticar, sin arrestos de ideólogo político, un movimiento de autonomía, que en corto plazo había de producirse, por acción de los inquietos criollos y mestizos, en diversas regiones de América, desde México hasta el sur. A su vez estimuló con sus estudios y su ejemplar amor por la naturaleza de América, el sentimiento nacionalista en muchos «pro hombres» de la independencia, entre los cuales ocupaba un lugar preeminente en su predilección personal Simón Bolívar.

$\mathrm{D}$ e modo que si en lo científico la obra de Humboldt significa una total revelación de un mundo ignorado, al que por primera vez se aplica una investigación sistemática; en lo social importa la magna obra de despertar la conciencia de los americanos, en su espíritu y en su naturaleza, que incluye la explotación cabal de sus ingentes riquezas naturales intocadas.

Su mensaje humano se nutre de generosas ofrendas: el desinterés científico, pues carece de consigna política, de propósito de penetración, de interés por explotar riquezas para sí o para los suyos, de total entrega a la causa de la ciencia que no tiene fronteras y que sólo responde a ideales elevados. Multitud de viajeros anteriores, y aún contemporáneos y posteriores, provenientes de otros lugares de Europa, vinieron a América para estudiar planes de colonización o de explotación comercial, y acaso eran vigías o avanzadas de una 
política expansionista. Humboldt vino sin atadura política alguna, confiado en sus propios recursos económicos, y consta que perdió en la empresa americana, que abarcó casi toda su vida posterior, su fortuna personal y que para no mendigar tuvo que volverse cortesano en sus últimos tiempos. En su desprendimiento y abandono de todo cálculo de provecho material, Humboldt es ejemplar. Y lo es también cuando demuestra su capacidad de sacrificio personal, al poner en peligro su vida repetidas veces en esta empresa de atravesar regiones nunca halladas por el hombre o cuando descarta de su obra todo propósito personal de encumbramiento y comparte generosamente con sus colaboradores — durante el viaje y después en Europa - las glorias de los resultados de sus estudios, demostrando así, al par que su grandeza de espíritu, la suprema verdad de que no hay obra positiva de ciencia moderna que excluya la colaboración y el trabajo en equipo. El sabio solitario no puede ya desde la época de Humboldt ofrecer obra de validez universal. La totalidad de los fenómenos de la naturaleza y del hombre en cuyo estudio se aplicó Humboldt, requirió —a partir de él y por su iniciativa - la acción coordinada de muchos especialistas y la concertación de voluntades puestas al servicio del interés de la ciencia moderna.

Su lección sirve no tanto para que en lo sucesivo se imite su inquietud universal y totalitaria, cuanto para iniciar los estudios especializados que su genio señala a las nuevas promociones de científicos. Por eso, es que sus discípulos cercanos o lejanos, y la legión de viajeros científicos alemanes que vinieron en los ańos sucesivos del siglo xix y $\mathrm{xx}$ se caracterizan más y más por ser los especialistas de una determinada materia científica o cultural. Claro que han perdido el atractivo de la universalidad que adornaba a Humboldt, y que carecen acaso de la sugestión integral de su tarea (nutrida de naturaleza, vida y espíritu) empeñada en las más diversas direcciones. En cambio, han ofrendado los más preciados frutos en la investigación de las más variadas materias: en él hallamos a Tschudi y Middendorf en la lingüística antigua, Uhle en arqueología, Weberbauer en la botánica, Borchers en los escalamientos de montañas, Schweigger en la oceanografía, Sievers y Troll en la geografía científica, Steinmann y Petersen en la geología, Cunow y Trimborn en la historia, por mencionar figuras ejemplares. Nos obligaría a una enumeración fatigosa lo que hicieron sus discípulos en los demás países hispanoamericanos. La ciencia moderna ha engrandecido portentosamente, gracias a los especialistas, su campo de trabajo y sus proyecciones en beneficio de los hombres. Pero el espíritu humano vuelve en nuestros días a una aspiración de retorno hacia esa gran síntesis de los conocimientos adquiridos y tratará en un próximo futuro de recomponer ese cuadro de la totalidad del saber, de alcanzar esa

\section{GUADERNOS LTERARIOS}


cósmica visión del mundo a que aspira Humboldt en sus últimos días, acrecentada con el caudal inmenso, fragmentario y atomizado que en más de un siglo transcurrido desde su muerte ha adquirido el conocimiento humano.

Caltaría, sin embargo, reparar en un aspecto inadvertido seguramente para el propio Humboldt, en que la proyección de su obra rebosa el ámbito de la investigación científica naturalista o geográfica, y que emana de él como una refracción cultural invalorable. Indirectamente, influye la obra de Humboldt sobre los grandes creadores artistas y literatos del siglo XIX, promoviendo en los países hispanoamericanos el interés por una creación sustentada en el embrujo de la naturaleza de este continente. El paisaje y el hombre americano empiezan a constituir la preocupación de los escritos del romanticismo naciente, y se produce una sintonía entre Humboldt, producto de la generación del Sturm und Drang, de la Ilustración y de los autores de poesía y de prosa (que ensayan desde comienzos del siglo XIx una expresión literaria de contenido americano). Humboldt señala el tópico de la naturaleza romántica en sus grandes descripciones de fenómenos naturales y en la caracterización del personaje típico de estas latitudes. Descubre América para los ojos de los artistas americanos. Con ello eclipsa ese falso clasicismo que se había generado en la época virreinal. Antes que él, Chateaubriand y Bernardino de St. Pierre, muy leídos y asimilados por Humboldt, habían contribuido a ese descubrimiento de América para el arte, pero Humboldt precisa y fija más concretamente, con menos fantasía y euforia —aunque con más cabalidad - el paisaje de América para los americanos y también para los europeos. Desde entonces ya no será América la «utopía» de los escritores europeos del XVIII, sino la inspiración objetiva de los románticos.

Humboldt hace que América deje de ser una mera fantasía de los poetas y se convierta en un tópico concreto de los viajeros románticos, que aquí expansionan su espíritu curioso. Sus lecturas de Campe, Forster, Cook y de otros viajeros del siglo precedente habían hecho superar — en su espíritu - el aliento imaginativo y fantasioso de Rousseau, SaintPierre, Voltaire y Marmontel. Para destruir el continente de la utopía, Humboldt creó el continente de la esperanza. Nuevos ojos adquirieron los europeos para observar la vida americana como refugio de la fatiga de vivir y del dolor del mundo que aquejaba a los europeos de su época. 
Aquí, en América, esperaba a los europeos una naturaleza y un mundo en toda su frescura y en el esplendor de sus fuerzas nativas (al margen de las formas marchitas del Nuevo Mundo antiguo). Aquí podía ya refugiarse el espíritu de los nuevos hombres europeos volcados hacia el futuro. Aquí podía realizarse la esperanza en una humanidad mejor. Tratando del influjo de Humboldt sobre el proceso literario y cultural americano. Se ha escrito, con acierto, que el propio Humboldt, con el don lírico que embelleció su obra, forma en Hispanoamérica escuela de prosistas. Es el primero en despertar el entusiasmo por la valoración cabal de la naturaleza americana. Pero su paisaje no era simplemente el cuadro exacto que veía en la naturaleza. Sus dotes de poeta perfilaban los contornos, trazaban los relieves y adornaban románticamente los rasgos naturales. Ello no lo habían hecho nunca los viajeros que lo precedieron ni muchos los subsiguientes. Constituían sus descripciones y dibujos una mímesis interpretativa. Por algo sus obras más populares se titulan «cuadros» $\mathrm{y}$ «vistas». Resume en ellas la mirada del hombre que ama lo que ve y no simplemente que transcribe fríamente, que no sólo reproduce la naturaleza, sino que establece la armonía de la naturaleza con los seres animados que la pueblan. La suya no es solamente la mirada que analiza, sino además la mirada que — llena de sensibilidad — traduce con amor y con goce.

Hemos demostrado en otras páginas que Unanue, gran amigo de Humboldt y su contemporáneo de semejante estructura espiritual, era ya en los finales del siglo XviII un precursor del Romanticismo en sus escritos de juventud. Humboldt afirma la misma tónica con toda su autoridad de sabiduría y con el respaldo de sus afanes científicos. Humboldt no sólo contribuye a descubrir un sentimiento en la naturaleza americana, sino que va más allá; esto es, que desflora un motivo nuevo y romántico en la belleza natural y en el habitante típico —en el indio - adentrado en su espléndida tradición y en su angustia de hombre auroral. Debemos, por eso, reconocer en Humboldt la calidad de gonfalonero en el proceso de creación de una literatura propiamente americana, cuyo surgimiento y desarrollo es símbolo de una venidera nueva concepción de mundo y de una naciente cultura americana.

\section{GUADERNOS LITERARIOS}

